\title{
BI for accounting students
}

\author{
By Milton G. Ternberg \\ Social Science/Business Library \\ University of California, Berkeley
}

\section{Experimenting with online business databases in an accounting course.}

T o find information on a company is a typical assignment given in most business schools. Students are exposed to a variety of library resources, mostly in printed format. In most academic libraries, the rapidly growing number of sources in electronic format receive relatively little use due to factors such as cost or lack of publicity. This article describes a joint library/business school project to experiment with the use of online business databases in an accounting course.

In 1984, the School of Business Administration at the University of California, Berkeley, received financial support to test the usefulness of certain business databases in an undergraduate accounting course. The demonstration was funded by a teaching innovation grant provided by the University's Council on Educational Development. Among other interests, the Council has a current commitment to promoting computer literacy through faculty initiated teaching projects.

The grant application originated from a Business School faculty member's attendance at a faculty seminar on databases in the social sciences. After listening to presentations by three librarians, he immediately saw potential applications in his administrative accounting course. The course is designed to introduce undergraduates to the basics of accounting and to company financial analysis.

Before applying for the grant, he approached the Social Science/Business Library for assistance in preparing the application and for assurance that the library would be willing to participate. The jointly prepared application requested funding for online time, for salaries of two student assistants, and for production of a user's guide to business databases.

The demonstration was integrated into the course project, which involved a programmed assignment requiring the use of numerous company information sources in the library. Library staff had in previous semesters helped to develop the project and provided handouts guiding the students to the appropriate sources.

The goals of the online demonstration were: a) to expose students to online searching in a nonthreatening manner through the use of a search intermediary (librarian); b) to experiment with the usefulness of selected business databases in accounting education; c) to determine student reactions to the ease of online information retrieval and to the cost; d) to prepare a user's guide to business databases for distribution in the library; and e) to increase Business School faculty awareness of business databases.

The instructor and librarian began the project by deciding which types of information from the assignment to retrieve. Test samples were run in a variety of databases to evaluate the apparent usefulness of each database. The instructor's two assistants were given the task of preparing the user's guide. Since neither of them were familiar with online searching, the librarian had to educate them quickly in the basics of automated information retrieval. Nine sample searches to include in the 
guide were run in the following databases: Standard \& Poor's News, Disclosure II, Investext, Newsearch, ABI/Inform, Trade and Industry Index, PTS Prompt, PTS F\&S Index, and PTS U.S. Forecasts. The students were then set free to prepare the guide from their observations and from additional information provided. Several meetings were subsequently held with the librarian and instructor to review their progress and to make needed additions or changes. A draft of the guide was distributed to the class for comments, several changes were made, and the final guide printed for distribution to the faculty and to library users.

Prior to the actual demonstration phase, the librarian provided an introductory lecture on online searching. In addition, an MBA student, writing a paper on the actual use of databases in companies, spoke to the class on her findings from interviewing managers in various San Francisco Bay Area firms. This helped to legitimize the business use of online information retrieval in the minds of the students.

The class of 125 students was divided into twenty-four small groups for the demonstration phase. Each group was to inform the librarian of the company it was using and to make an appointment for a forty-minute session on their own time. The forty-minute sessions were scheduled over a three-week period.

The group sessions began with a brief review of online searching and what was to be accomplished. Since the librarian actually performed the searches, it was not necessary for the students to understand in great detail the searching protocols.

Five different databases were used to retrieve selected types of information the students had previously been required to search for manually. The content of each database was discussed before going into it. Newsearch was used to locate very current articles on the group's company, Standard \& Poor's News provided financial statements, Disclosure II produced a list of officers and their salaries, and $A B I /$ Inform or Trade and Industry Index was used to locate articles on a significant corporate event, such as merger or stock split.

Each student had initially been required to find very current articles about the company being researched. The librarian asked where they had looked for articles and how successful their search was. The name of the company was then entered into Newsearch to demonstrate the ease of locating very current articles.

Most of the course assignment involved working with a company's financial statement. One of the requirements was to locate the company's latest quarterly earnings report. Most of the students had used in hardcopy Standard \& Poor's Corporation Records Daily News and Cumulative News. The online version was demonstrated to show that it was possible to print the report and to allow the students to compare the currency of the report with the one they had found in the hardcopy format.

The most challenging aspect of the assignment involved locating salaries for the top executives of the company. Prior to the library's acquisition of proxy statements, this proved to be a difficult aspect of the assignment for both the students and the library staff. The Disclosure II database was used to print out the names of officers and their salaries. This aspect of the demonstration seemed to impress the groups most because of the difficult time they had had finding the information manually.

The last aspect of the online phase involved searching for a corporate event which had a significant effect on the company's finances. ABI/Inform and Trade and Industry Index were used for this purpose. When possible, $A B I /$ Inform was used to show the availability of abstracts in some bibliographic databases.

At the end of the semester, the instructor asked the students in the course to evaluate the usefulness of the demonstration to the course assignment and to react to the cost of their group session. The students were impressed with the ease with which information could be retrieved and its usefulness in completing their assignments. Even though each group online session averaged only $\$ 30$, most students indicated that they would not be willing to spend their own money on the service.

The demonstration proved that selected business databases do have applications in an undergraduate accounting course. They enable students to locate quickly certain types of information, which would normally require considerable manual searching. However, the further use by the course instructor and other business faculty has not happened, primarily because of the students' negative reaction to the cost. Most faculty are reluctant to require students to spend money for information.

When trying to advocate the use of online searching in business education, the cost always becomes the negative factor. The connect hour charges, designed for private business use, prohibit the widespread use of databases in education. Reduced online costs for educational purposes would allow business librarians to prepare better for the future corporate users of online business information.

\section{Historical society libraries}

A panel entitled "Historical Society Libraries" is one of the sessions planned by the ACRL Rare Books and Manuscripts Section's Continuing Education Committee for the 26th ACRL Rare Books and Manuscripts Preconference in Chicago, July 2-5.

This session, scheduled for Friday, July 5, at 11 a.m., will provide a forum for discussion of the challenges and opportunities presented to library professionals in this field. Contact: William B. Keller, Head Librarian, Maryland Historical Society, $201 \mathrm{~W}$. Monument St., Baltimore, MD 21201; (301) 685-3750. 